\title{
HISTÓRIA COMO RUPTURA: ORGANIZAÇÕES HISTÓRICO-TEMPORAIS E OS TRÊS MOVIMENTOS DA EXISTÊNCIA DE JAN PATOČKA
}

\author{
History As Rupture: Historical-Temporal Organizations And The Three Movements Of The \\ Existence Of Jan Patočka
}

Historia Como Ruptura: Organizaciones Historico-Temporales y Los Tres Movimientos de la Existencia de Jan Patočka

\author{
Gabrielle Mesquita Alves Rosas \\ Universidade Federal Fluminense
}

\begin{abstract}
Resumo
O autor Jan Patočka entende história como ruptura. A ruptura entre história e pré-história acontece como movimento autêntico de nossa natureza humana. Movimento, usado em conotação qualitativa, é lido como transformação, como possibilidade. Afirma-se a existência de três movimentos individuais que de maneira transubjetiva se transformam em horizontes históricos. A autenticidade da transformação advém da consciência da natureza humana dos três movimentos individuais - ancorados em nossa corporeidade - e da responsabilidade da criação de horizontes transubjetivos - desta forma, históricos. Para melhor entendimento dessas ideias, trazemos a leitura de François Hartog e sua noção de regimes de historicidade compreendida como identificação e nomeação de diferentes organizações histórico-temporais.
\end{abstract}

Palavras-chave: Filosofia da História; Fenomenologia; Genealogia da Responsabilidade; regimes de historicidade.

\begin{abstract}
The philosopher Jan Patočka understands history as a rupture. The rupture between history and prehistory occurs as an authentic movement of our human nature. Movement, in its qualitative connotation, is read as transformation, as possibility. He establishes three individual movements that transform themselves, by a trans-subjetive mode, into historical horizons. The authenticity of this transformation comes from the consciousness of the human nature of the three individual movements - anchored in our corporeity - and from the responsibility on the creation of transubjective horizons - thus historical. To better understand these ideas, we bring François Hartog's notion of regimes of historicity understood as a form of identification and naming different historical-temporal organizations.
\end{abstract}

Key-words: Philosophy of History; Phenomenology; Genealogy of Responsibility; Regimes of historicity.

\section{Resumen}


El filósofo Jan Patočka entiende historia como ruptura. La ruptura entre historia y pre-historia sucede como movimiento auténtico de nuestra naturaleza humana. Movimiento, usado en connotación cualitativa, se lee como transformación, como posibilidad. Se afirma la existencia de tres movimientos individuales que de una manera transubjetiva se transforman en horizontes históricos. La autenticidad de la transformación adviene de la conciencia de la naturaleza humana de los tres movimientos individuales - anclados en nuestra corporeidad - y de la responsabilidad de creación de horizontes transubjetivos - es decir, históricos. Para una mejor comprensión de estas ideas, traemos la lectura de François Hartog y su noción de regímenes de historicidad comprendida como identificación y nombramiento de distintas organizaciones histórico-temporales.

Palabras-clave: Filosofía de la Historia; Fenomenología; Genealogía de la Responsabilidad; Regímenes de historicidad.

Jan Patočka foi um filósofo que contribuiu bastante para a fenomenologia na Europa Central, nascido em Turnow, ainda antes da formação da Tchecoslováquia, atuou como professor na Charles Univesity e também é um dos autores da Charter 77, reconhecido documento assinado por intelectuais e estudantes pedindo aos dirigentes tchecoslovacos para aderir aos princípios de direitos humanos propostos pela ONU em 1948. Parte da importância de sua contribuição está no fato de que levou sua filosofia às ùltimas consequências, sendo ele mesmo vítima da violência por defender que "há coisas pelas quais vale a pena sofrer" (Patočka, citado por Terril, 2014, tradução nossa). Patočka morreu de derrame cerebral em decorrência de um interrogatório de onze horas por parte da StB (Polícia Secreta do Partido Comunista da Tchecoslováquia).

Suas ideias iam contra o niilismo e a falta de significado da vida pois acreditava que a filosofia é, ainda que no seu pico mais teórico e abstrato, muito que mais teoria e abstração. A habilidade de poder escolher como vivermos nossas vidas inclui riscos, mas, esse risco tem significado se se torna claro que a soberania sobre nós mesmos é inviolável, sagrada, algo incondicional que até mesmo Estados e sociedades estão sujeitos a aceitar. Nossas vidas carregam o testemunho da verdade, o que é de fato ser humano. E, por isso, há alguma responsabilidade na escolha de como viver a vida. A ideia de responsabilidade é central em sua teoria dos movimentos, mas é ainda mais explícita em um documento que escreveu chamado "A Obrigação de Resistir à Injustiça". Patočka estava de acordo com a ideia de Platão de acreditar que ao homem foi dado alma para construir um mundo de verdade e justiça, bem e mal é algo que deveriam nos preocupar (Terril, 2014).

Como veremos, Patočka tentou explicar que havia algo de pessimista em Platão e, estando infeliz com a sua noção de mundo natural, se empenhou na tarefa de entender o que seria o horizonte vivido. Contudo, antes de tratarmos especificamente das ideias de 
Patočka, entendemos ser importante uma discussão sobre o tempo e as diferentes formas de pensá-lo em diferentes momentos, sociedades e lugares. Como base nos utilizamos da obra do autor François Hartog (2003) que explica diferentes organizações históricotemporais através da noção de regimes de historicidade. A análise temporal de Hartog (2003) se empenha na difícil tarefa de analisar o contemporâneo contemporaneamente. Para isso, parte da atual crise de grandes modelos analíticos, chamada às vezes de pósmodernidade, para trabalhar a questão da falta de orientação ou necessidade dela como principal resposta que sobra da grande problematização teórica chegada à ciência ocidental no fim do século XX. Seu desenvolvimento não somente é interessante por ajudar a entender algumas crises contemporâneas (de representação, da democracia, das instituições, da ciência etc.) como nos ajuda a compreender o desenvolvimento que faremos em direção aos três movimentos da existência contido na obra de Jan Patočka.

\section{REGIMES DE HISTORICIDADE}

Hartog (2003) propõe uma noção de regimes de historicidade para entender diferentes noções de tempo ao longo de diversos momentos da história da humanidade. Combinações diferentes entre passado, presente e futuro organizam uma noção específica de tempo e história e, eventualmente, essas disposições histórico-temporais se alteram, trazendo uma nova forma de encarar e conceber o que seja história. Um marco segundo o autor é 1989. Para além de outros marcos como a queda do muro de Berlim, aponta o rápido alastramento das ideias de Fukuyama em 1995 como um sintoma de que a história já não era mais concebida ao modo como veio sendo desde 1789. O conteúdo do livro de Fukuyama em si não fala tanto quanto a alta receptividade às ideias de fim da história. $A$ ideia de "fim da história" marca com bastante clareza a alteração da noção históricotemporal vigente até aquele momento.

Esse período entre 1789 a 1989 é apresentado por Hartog (2003) como regime moderno de historicidade e nele, vem do futuro uma admoestação para o presente, a lição da história está no futuro e daí vem a necessidade de previsão tão premente no período. É nesse regime que se concebe A História, história unívoca, uma noção de que além das muitas histórias existe Uma História que a partir de então acontece não apenas no tempo mas também pelo tempo. Neste, o futuro se desvincula de tudo que as antigas experiências foram capazes de trazer ao presente, bem como as experiências presentes já não são capazes de servir de base para as expectativas de futuro. Há uma soma de histórias singulares em um único enredo comum, é um tempo sem sujeito no qual a história se torna mestra de todas outras ciências e cria a noção de que a história é agente do destino humano e do progresso social com horizonte de expectativa ilimitado, lema para a luta e 
integração social. É uma composição feita através de dois campos do saber: um objetivo (acontecimento) e outro subjetivo (conhecimento) que altera a importância do passado, o conceito de História se "estica" e passa a cobrir todas as extensões temporais possíveis.

Outro regime de historicidade tratado pelo autor é reconhecido como historia magistra vitae. Este regime é marcado pela ideia de que o futuro é regulado pelo passado, não exatamente um futuro que reproduz o passado, mas um futuro que não vai muito além do passado. Usa como exemplo uma frase de Tocqueville para se referir à Revolução que estava em curso (revolução francesa): "Quando o passado não mais lança luz sobre o futuro, o espírito caminha nas trevas". A história assim vista é mestra da vida e o que Tocqueville registra é justamente o choque ante à nova organização histórico-temporal (regime de historicidade moderno) que não se ancorava no passado para conceber o futuro. No regime historia magistra vitae percebe-se uma autoridade do passado, a imitação tem um papel, é como se olhando para trás se pudesse ver também o futuro.

Hartog (2003) se empenha em dizer que por regime não pretende circunscrever um período exato ou a existência de apenas um regime por vez. Assim, mostra como mesmo antes da transição do regime moderno de historicidade já despontavam certos questionamentos acerca deste. A crítica ao Historismus ou história positivista, a tentativa de Benjamin de elaborar um novo conceito de história, investidas para voltar ao passado com novas perguntas e assim tirar dele "um novo passado". O autor também delineia o que chama de presentismo, tendência expressiva que se apresentou junto a essas outras ao fim do regime moderno de historicidade.

Por presentismo entende uma progressiva invasão do horizonte por um presente inchado que seria fruto da separação entre experiência e expectativa criada durante regime moderno de historicidade. As críticas ao futurismo e as desilusões com o progresso servem do fomento ao que chama de "retiro no presente". Assim, slogans como "esqueça-se do passado", "tudo para agora", "sem futuro" registrados nos muros de Paris em maio de 1968 tornam-se marcantes e crescentes. O autor afirma que é uma valorização do presente diferente do carpe diem ou daquela apresentada por Montaigne. É um presente que cresce inexorável e que por apoio do mercado passa a deixar tudo rapidamente obsoleto. Assim, passa-se a crer que não há um horizonte, nem passado e nem futuro, ou ainda, torna-se claro uma nova necessidade de criar um novo passado e novo futuro muito rapidamente. Para atestar isso usa exemplos da forma como lidamos com a morte (já não há um lugar para os mortos na história), extrema valorização da juventude, técnicas para suprimir o tempo (tempo do computador $\mathrm{x}$ tempo real). $\mathrm{E}$ já como consequência do presentismo (despontando para críticas a este, ou, para um novo regime de historicidade) a imagem de um passado exótico que deve ser preservado em forma de patrimônio, uma ansiedade de 
conservação de monumentos, uma inquietude com a ideia de esquecimento. Um vazio que busca identidade juntamente com um retorno ansioso para o futuro que resume assim:

Em quem você vai votar nas próximas eleições? o que você acha hoje imaginando o que você achará daqui a seis meses, e o que forem os resultados daqui a seis meses, eles são já os resultados. A pesquisa é uma ferramenta de previsão do futuro sem, por assim dizer, deslocar-se do presente. É uma fotografia, que de certo modo suprime o tempo. Mas, como sabemos, acontece que as pesquisas se equivocam! (Hartog, 2003, p. 28).

Uma coisa interessante de se notar é que a noção de regime de historicidade, apesar de não querer se apresentar como conceito, somente é possível ser formulada quando a noção historico-temporal corrente permite um distanciamento de si para a criação de uma análise. E, apesar de citar Mesopotâmia e Grécia como exemplos de pré-história da historicidade com sistemas de adivinhação (e noções de futuro como passado: oráculos já descrevem o futuro como passado) e épica (ideia de memória social para uma morte que traria glória imortal); expõe a necessidade de se conhecer mais noções como essas antigas bem como outras, orientais e as do antigo Leste.

Com o intuito de expandir nosso conhecimento sobre diferentes organizações histórico-temporais, refletimos sobre Platão e a tradição filosófica ocidental em direção às ideias de Patočka. Hartog (2003) aponta que refletir sobre outros regimes de historicidade possíveis ajuda a pensar a situação contemporânea, então, refletir sobre uma história na qual se pensa o coletivo sim, mas sem deixar de incluir o sujeito, como formulado por Patočka, possa ser um caminho para entender o pedido de novas orientações (ou entender a sensação de falta de orientação) sentidas no presente.

\section{PLATÃO, A TRADIÇÃO FILOSÓFICA OCIDENTAL E O DISCURSO CIENTíFICO NO COTIDIANO}

Quando se fala em "afastamento de si mesmo" para a análise de determinado fato, voltamos à Platão. Antes do apogeu das civilizações, a percepção de progresso que dotasse a ação humana de intencionalidade rumo a uma mudança ordenada era inexistente. O "triunfo das civilizações" altera o estado dos povos que estavam envoltos em atmosfera de experiências e mitos no qual a existência singular era menos importante que o princípio fundador de todas as coisas. Assim, sofistas e Platão são reformadores da cultura grega, seu pensamento é a semente de uma sociedade dinâmica que irá se fundar no que era a oposição de um estilo rudimentar de adaptação cega às necessidades básicas do homem. A 
importância de Platão é tal que se chega a afirmar que a tradição filosófica do ocidente pode ser entendida pela metáfora de que são notas de rodapé ao pensamento platônico (Teixeira, 1959).

Para Platão, o Estado iria se fundar na educação e no treinamento dos indivíduos para que estes fossem capazes de atender a diferentes funções sociais que lhes fossem reservadas. E este treinamento era feito com exaltação da razão, considerada mais real que as coisas mundanas e passageiras. Os efeitos desta dualidade razão versus sentidos se tornam tão marcantes que ainda hoje, ainda que com oscilações entre filosofia e outra, está presente em filosofias contemporâneas. O conhecimento fora hierarquizado, o racional (simétrico, harmônico, do espírito, contemplativo e ligado ao prazer) era destinado aos homens livres; o empírico (de experiência e erro, incerto) era destinado aos escravos. As teorias sobre o homem e a liberdade se fincam nesta dualidade.

Pela teoria platônica, a natureza não chegava a ser digna de estudo e os homens estavam todos distribuídos em três classes, apenas, de indivíduos, conforme atingissem os dois únicos níveis de desenvolvimento além do nível dos simples apetites do corpo. Aos desse último grupo caberia o trabalho, para atender às necessidades da matéria; aos que, ultrapassando os apetites, alcançassem a coragem e a generosidade, competia a defesa da sociedade; e, finalmente, aos que se elevassem ao estágio da razão e da visão universal, o poder e o governo (Teixeira, 1959).

A educação serviria então para desvendar as potencialidades dos indivíduos e distribuí-los pelas diferentes classes. A apropriação cristã de tal pensamento traria duas novidades, embora não alterasse "a grande estrutura do mundo", quais sejam, i) a natureza passa a ser respeitável e constitutiva do ser humano e ii) o embate carne e espírito como sendo a luta de todos os homens e não somente privilégio de alguns. Esta segunda formulação leva a um princípio democrático, devido à apontada igualdade entre os homens e da primeira formulação surge o estudo da forma, baseado na ideia de que a natureza é criação do ser perfeito ou Deus. O dualismo platônico conciliado com a doutrina judaicocristã daria origem às filosofias modernas de Bacon, Descartes, Locke, Kant, Fichte e Hegel; todas oriundas e destinadas a completar o filósofo grego frente aos avanços da sociedade e conhecimentos humanos (Teixeira, 1959).

Como podemos ver, para Platão a educação tinha papel importante e, pensando a metáfora de que a tradição filosófica ocidental é quase uma nota de rodapé de Platão, da exacerbação dos ideais da filosofia moderna vemos a exaltação da ciência espelhar-se na educação e por consequência em nosso mundo cotidiano. Com o mesmo pano de fundo, 
nossas sociedades ocidentais contemporâneas têm pilares comuns e, ainda que hajam renovações, elas continuam a ter certas características em comum. Para citar o caso do imbricamento educação, ciência e democracia, no fim do século XIX, no auge do regime moderno de historicidade, o movimento pela Escola Nova pregava esses três ideais a fim de preparar as pessoas para o crescente desenvolvimento industrial. Gestada ao fim do século XIX na Europa, a ideologia depois migra para os EUA e chega no Brasil por 1920 (Peixoto, 1998). Pequeno exemplo da circularidade das ideias em nossas sociedades ocidentais.

Sucessivamente essas ideias, ainda que renovadas, ecoam e podem facilmente ser percebidas na vida comum, cotidiana. Trazemos aqui a reflexão de L'ubica Učník, professora de filosofia que tenta mostrar até que onde o ponto de vista científico consegue entranhar em esferas às quais não pertence e nas quais às vezes nem produz sentido ou destitui as coisas de outros possíveis significados.

Em seu intento de mostrar a descrição científica dos objetos, a autora nos serve com um exemplo do astrofísico Arthur Eddington. Este, ao iniciar suas aulas do curso de "Natureza Física do Mundo", mencionava uma duplicidade dos objetos que estavam a sua volta e para exemplificar sua ideia, descrevia duas mesas - que na verdade se tratavam de uma única mesa, a mesa na qual ele senta para se preparar para as aulas. A primeira mesa, a mesa que the era familiar, era descrita como uma mesa com extensão, comparativamente permanente, com cor e sobretudo substancial. Assim como uma descrição descartiana de que a natureza substancial dos corpos é extensão em comprimento, largura e profundidade. Já a segunda mesa, chamada de sua mesa científica, é descrita como composta sobretudo por vazios e, escassamente espalhadas por esses vazios, numerosas cargas elétricas circulando com grande velocidade e com massa bem menor que um bilionésimo da massa da própria mesa. Ainda que com essa estranha constituição, ela se tornava uma mesa inteiramente eficiente pois suportava o papel no qual ele escrevia de maneira satisfatória. Assim como a primeira mesa descrita, ainda que ele o fizesse sobre as pequenas partículas elétricas de longo alcance e ainda que estas continuassem a tocar o verso do papel, o papel se mantinha com sua forma e muito próximo da estabilidade. E mesmo que Eddington se debruçasse sobre a mesa seu corpo jamais a atravessaria, e para ser bastante exato, afirmava que as chances do cotovelo dele atravessar a mesa eram tão excessivamente pequenas que até poderiam ser negadas na vida prática.

Učník (2013) então se pergunta se as mesas são duplicadas ou se elas são duas descrições da mesma coisa. E para exemplificar, mostra como seria a descrição de sua própria mesa familiar:

Minha mesa está na cozinha e eu tomo café da manhã nela todas as manhãs. É uma mesa que une pessoas quando elas vêm me visitar e estamos de acordo 
com o que falamos. Ela também parece nos dividir quando discordamos. Mas ela está sempre entre nós, familiar e confiável: para por xícaras de café em cima; ou na verdade para qualquer propósito que nós poderíamos usar em diferentes momentos. Me sento à mesa quando estou feliz, assim como quando estou triste e minhas memórias vem correndo quando eu a vejo. Ela esta ligeiramente danificada de um lado do tempo que minha filha tentou escalá-la e a mesa tombou nela. Anos depois minha filha não tem nenhuma cicatriz, já a mesa nos lembra desse evento pelo arranhão manteve desde então: é uma memória em evidência. Eu gosto de acariciar essa mesa cheia de arranhões, já que me lembra de todas as pessoas que sentaram aqui alguma vez e também imagino que outros sentarão aqui algum dia no futuro. Não é apenas uma mesa útil onde tomo café da manhã, é uma parte da minha vida (Učník, 2013, p. 34, tradução nossa). ${ }^{1}$

Ainda sobre a descrição das duas mesas, Eddington afirmava que revendo as propriedades das mesas não havia motivos para escolher entre uma das duas, porém, em circunstâncias anormais a sua mesa científica parecia apresentar vantagens. Se por acaso sua casa pegasse fogo, sua mesa científica se dissolveria quase que naturalmente em fumaça científica, enquanto sua mesa familiar se metamorfosearia mudando sua natureza substancial de maneira quase milagrosa ao olhar. Assim, o sentido de substancialidade da mesa é muito diferente para Eddington e Učník, como a autora mesmo comenta, sua mesa era também estável e também não permitia que um cotovelo a atravessasse, ainda que fosse surpreendente que a mesa se movesse numa direção indesejada quando foi forçada por sua filha. A substância para Eddington estava ligada à concepção intrínseca da natureza e assim a descrição daquelas mesas eram tão generalizantes que poderiam ser a descrição de qualquer mesa ou mesmo objeto que possuísse extensão no espaço. $E$ isto se dava pois a descrição da mesa atende ao método da física clássica.

O que a leva a se perguntar: como essa substituição de leitura acontece, por que é difícil perceber que a leitura teórica e estrutural do mundo só é útil para previsões científicas e não aplicável para a nossa vida mutável vida cotidiana?

\footnotetext{
${ }^{1}$ My table is in the kitchen and I have my breakfast at it every morning. It is a table that unites people when they come to visit me and we talk in agreement. It also seems to divide us when we disagree. But it is always in between us, familiar and dependable: to put cups of coffee on; or indeed for whatever purpose we might use it at different times. I sit at that table when I am happy as well as when I am sad, and many memories come rushing in when I look at it. It is slightly damaged on one side from the time my daughter tried to climb up onto it and the table toppled onto her. Years later, she has no scars left, but the table reminds us of this event by the scratch that has remained there ever since: it is a memory writ large. I like to stroke that chipped table, as it reminds me of all the people who sat there once upon a time; and I imagine that others will sit there sometime in the future. It is not just a useful table that I have breakfast at; it is a part of my life (Učník, 2013, p. 34).
} 
Outros exemplos que a autora usa estão relacionados a ideia de determinado geneticamente: "nossos cérebros estão geneticamente programados para a felicidade", "podemos melhorar a performance de nossos hábitos se soubermos como funciona nossa genética", "acreditar em Deus é também resultado de determinação genética", manchetes em jornais e revistas. Cita ainda a "revista eletrônica para mentes evoluídas" uma publicação de "Life as A Human Inc" e uma de suas matérias "Somos condicionados geneticamente a cuidar e a nos relacionar".

O questionamento feito vai além do simples apropriar-se de uma linguagem científica mas refletir até que ponto o método científico está sendo usado para interpretar a vida cotidiana, ou, até que ponto um método que serve a algumas ciências está sendo usado indiscriminadamente para explicar fenômenos que não estão sendo pensados dentro de um contexto científico. A autora pergunta, o que seria flogisto ${ }^{2}$ ? $\mathrm{E}$ afirma que a menos que se tenha muito interesse em história das ciências, esta é uma pergunta sem sentido. Hoje porém, falamos em oxigênio e combustão justamente porque os métodos mudaram radicalmente. $O$ interessante seria então ter em mente os axiomas que estão por trás dessas leituras que fazemos da realidade, para não operarmos com símbolos de forma problemática justamente porque não sabemos de que ponto de vista se parte ao nos utilizarmos de determinado método. E citando Husserl afirma "Ciências de mentalidade meramente factuais produzem pessoas de mentalidade meramente factuais".

Outro ponto levantado pela autora é: porque quando não se fala em ciência se fala em religião/crença? Desde quando estas são as duas únicas possíveis visões de mundo? E por que nos acostumamos que sejam apenas duas ou por que não admitimos que é possível outras perspectivas?

Discordar da ciência é necessariamente cair no mundo das crenças? Não ter nenhuma crença é necessariamente crer na ciência? Patočka afirma que quando já não conseguimos nem respostas a certas perguntas, nem formular novas perguntas, o que precisamos é de um novo plano de fundo para dar base ao nosso entendimento.

Quando a base (ground) do nosso pensamento começa a ficar instável, os significados ficam problemáticos; as perguntas e respostas perdem a familiaridade que tinham antes. Mas nós não podemos viver sem significados. Então, ou nos agarramos às antigas questões e respostas, que agora estão vazias de significado, ou aceitamos a problemática e começamos a procurar por novas perguntas que nos darão novas respostas. Perguntas, no entanto, sempre

\footnotetext{
${ }^{2}$ Teoria antiga que afirmava que nos corpos em combustão haveria uma matéria, o flogisto, que seria liberado no ar durante a queima.

${ }^{3}$ Merely fact-minded sciences make merely fact-minded people.
} 
dependem da base que nunca questionamos. Para que possamos abrir para um novo modo de pensar, precisamos começar questionando a nossa base. Isto é uma das tarefas mais difíceis, já que somos, na maior parte do tempo, cegos para aquilo que ora pressupomos. Em outras palavras, apenas quando a base de nosso pensamento está irresolutamente rompida nos tornamos alertas sobre as questões que temos à mão não serem adequadas aos problemas que estamos tentamos lidar. Como afirma Patočka, precisamos mudar a base a fim de perguntar diferentes questões, porque o que é problemático é, na verdade, a base da qual nossas perguntas vêm. (Učník, 2013, p. 44, tradução e grifo nossos). ${ }^{4}$

Mudar a bases do pensar, no entanto, não é tarefa fácil, como pudemos ver é de longa data nossa tradição não só do pensar científico que nos acompanha desde início da modernidade, mas da própria valorização da razão enquanto forma privilegiada do pensar que remonta à antiguidade. E aqui a questão não é por de lado a ciência em nome de uma outra visão de mundo, nem hierarquizar perspectivas entre melhores ou mais verdadeiras visões de mundo pois isso não parece valorizar o ser humano em sua inteireza. Ser humano não é apenas ser dotado de capacidades mentais racionalizantes, é, dentre muitas características, possuir sentimentos não racionalizáveis que irão influir em nossos juízos podendo nos deixar confusos, indecisos; complexidade que é difícil ser representada aos moldes do pensamento racional.

Nesse sentido, voltar-se às necessidades humanas e refletir possíveis formas de acomodação dessas necessidades nas práticas correntes do nosso cotidiano parece ser o primeiro passo para fazermos novas perguntas com vistas a mudar a base do nosso pensar. No formato atual, o cotidiano familiar é menos "natural" e está mais para a descrição da mesa de Eddington. Recuperar o olhar humano, com sentimentos e incompletudes parece vital para recuperar a "naturalidade" do ser humano no mundo.

\section{DOS MOVIMENTOS DA NATUREZA HUMANA AOS TRÊS MOVIMENTOS DA EXISTÊNCIA}

\footnotetext{
${ }^{4}$ When the ground of our understanding becomes shaky, meaning becomes problematic; questions and answers lose the familiarity that they had before. But we cannot live without meaning. So, either we cling to the old questions and answers, which have become empty of meaning, or we embrace this problematicity and start looking for new questions, which will give us new answers. Questions, however, always depend on the ground that we never question. In order to start opening up the space for a new way of thinking, we need to begin by questioning the ground. This is the most difficult of tasks, as we are, most of the time, blind to that which we nevertheless presuppose. In other words, only when the ground of our understanding is irresolvably disrupted do we become aware that the available questions are not adequate to the problem at hand. As Patočka says, we need to shift the ground in order to ask different questions, because what is problematic is, in fact, the ground from which our questions came (Učník, 2013, p. 44).
} 
Patočka discute o que seria a natureza humana pensando em três movimentos da experiência humana. O que inicialmente pensa como fenomenologia "a-subjetiva" (diferenciando-se do que seria a fenomenologia subjetiva de Heidegger) como forma de afastar-se do excessivo foco na tensão sujeito-objeto na fenomenologia e passar a pensar como fenomenologia transubjetiva em seus últimos escritos. Sua mudança de perspectiva tensiona esfera individual e coletiva. A ideia de movimento vem de seu entendimento de que a manifestação dos fenômenos é dinâmica e não-subjetiva, e querendo problematizar o que seria a extrema ênfase na humanidade nos escritos sobre o homem-no-mundo, afirma que para fazer justiça à pluralidade das condições humanas (de modo, de lugar, dimensões...) toda e qualquer antropologia requer sociologia. A "abertura" do ser-no-mundo seria abertura a horizontes transubjetivos que são históricos, se manifestam no imaginário cultural e se concretizam nas instituições. Divide os movimentos em três, sendo que o último deles seria um que acaba por englobar os dois primeiros, o movimento de emergência da "verdade" do ser humano, de natureza transubjetiva, histórico (Adams, 2012).

Movimento é pensado por sua característica qualitativa (em oposição à parte quantificável que é locomoção, uniforme, estático e etc.) que é transformação. Para explicar os três movimentos, a autora Suzi Adams os explora em sua versão inicial, nos escritos anteriores à ideia de transubjetividade. As ideias de movimento baseadas na corporeidade serão retrabalhadas e reapresentadas sob aspecto histórico. Apresentaremos então os movimentos em sua versão inicial, para depois repensá-los em sua dimensão transubjetiva.

\section{MOVIMENTOS INDIVIDUAIS}

Um dos movimentos é baseado nas ideias de Bergson. Pensado como uma estrutura temporal vivida perpetuamente, seria organizado por uma unidade interna e sintética, assim como uma melodia, desdobra a experiência vivida no presente sobre o que resta de cenários vividos anteriormente, permitindo o passado fluir no presente e o antigo perdurar no acúmulo presente do que "tem sido". É o acúmulo passivo de experiência, base da vida. Outro movimento é uma releitura do que era movimento para Aristóteles, o movimento aqui é pensado como a transformação, possibilidade de se realizar. A vida como realização de possibilidades, o objetivo de qualquer movimento individual. Ao contrário do movimento anterior que recai no passado, este movimento é em direção ao futuro. $E$ um terceiro movimento, dado que todo movimento só ocorre por ligações internas, destaca a experiência vivida na corporeidade e a dinâmica como possibilidade que pega o que é dado para dentro de si e forja um significado unificado.

Uma noção de cuidado é também apresentada como tríade desses movimentos interrelacionados (em oposição a Heidegger que considera o cuidado como momento triplo) e o cuidado como revelação de nosso contato com as coisas, o cuidado nos leva às coisas 
com as quais lidamos e modificamos. Na tríade, o primeiro movimento é denominado de ancoragem ou raízes aprofundadas, o segundo de auto-sustento ou auto-projeção e o terceiro de transcendência. Destaca-se ainda a corporeidade, cada movimento compreende uma dimensão temporal distinta, tem um referente particular e aparece de modo autêntico ou inautêntico.

A ancoragem que seria referente ao passado é um movimento instintivo e afetivo de harmonia com o mundo, exerce controle sobre nosso corpo e "permite o mundo para nós" tendo a terra como referente de base imóvel e inabalável. Sua contingência é biológica, situacional, individual e personalizada. Se mostra inautêntico em contato com o segundo movimento quando este é reprimido pelo sentido "pragmático e utilitarista" do mesmo. $\mathrm{O}$ auto-sustento vai falar da esfera não intencional da produção e reprodução da vida enquanto existência nas coisas, "nosso corpo inorgânico" na esfera do significado. Corresponde ao presente e a objetividade do que é dado em forma de coisas. Neste domínio as pessoas são anônimas e reduzidas a seus papeis sociais. Seu limite está no conflito e no sofrimento porque sua inautenticidade ocorre pois, reduzidas a seus papeis, as pessoas falham em entender a si mesmas. Se auto-realiza na finitude humana, submetido às regras do "poder" da Terra. A transcendência visa conferir "encerramento" global aos dois movimentos anteriores e significado às regiões e ritmos destes. Chamado de movimento da verdade, tenta integrar finitude, situacionalidade e coisas para as quais antes estávamos cegos. É neste movimento que o mundo não é mais terra. Como movimento que é em direção ao futuro sua inautenticidade se dá pela nossa finitude. E aqui a existência não é nem enraizada, nem prolongada, ela integra.

No processo de transformação desses movimentos da corporeidade em movimentos que partilhamos com outros via transubjetividade (usada ao invés de sociabilidade) cria-se o que seriam horizontes históricos. Assim, pensar os movimentos coletivos é pensar mais na "abertura" (aos horizontes transubjetivos) instituída como condição de ser no mundo do que na condição humana corporificada no self. O mundo só se afirma historicamente no domínio social, pois é assim que se revela, e é assim que emerge em nossa abertura aos horizontes, histórico e não passível de ser compreendido nem via materialismo, nem via idealismo. Os três movimentos que levam a horizontes históricos seriam totalidades do comportamento humano, de seus pressupostos e suas sedimentações.

\section{MOVIMENTOS COLETIVOS}

O primeiro movimento coletivo seria não-histórico denominado aceitação, neste a ideia de "interessado" (oposto a indiferente) da corporeidade é substituída por demanda de convivência com os outros e justiça. O exemplo utilizado é da família patriarcal na qual o pai 
cria uma criança junto a si e lhe oferece horizontes de temporalidade, dando a esta criança não apenas o próprio corpo como o corpo social em nível micro. "O pai, erguendo do chão o bebê posto a seus pés, realiza um ato de aceitação que guarda nele uma relação com todos os horizontes da temporalidade" (Patočka, citado por Adams, 2012, p. 34, tradução nossa).

O segundo seria pré-histórico denominado defesa, é orientado ao presente e oscila entre o que dá alivio e, ao mesmo tempo, é oneroso. O exemplo utilizado é a dos impérios antigos dos quais se erigiram a escrita e memória petrificada gerando nova possibilidade de presença de longa variação e alcance.

O terceiro seria o histórico, denominado de movimento da verdade, é o que reconstrói o passado anônimo e a memória cultural coletiva dos movimentos anteriores. Esta apresentação dos três movimentos em Patočka reconfigura a ontologia político-social de Hannah Arendt de "labor, trabalho e ação". Para Arendt, a condição humana é dada pela ação do homem, revelando quem ele é e sendo necessária para que este inicie seus processos. Já Patočka mostra o encadeamento dos três movimentos como liberdade de ação humana: esta nova possibilidade é baseada no reconhecimento mútuo dos homens enquanto livres e iguais, reconhecimento que deve ser continuamente encenado e no qual a ação não tenha caráter forçado de trabalho como labuta mas, ao invés disso, manifestação de excelência.

Tal vida não procura escapar à sua contingência, mas também não the cede passivamente; desde que vislumbrou a possibilidade da vida autêntica, isto é, a vida como um todo, o mundo se abre para isso pela primeira vez - já não é meramente um plano de fundo involuntário contra o qual nos preocupamos quando este se mostra, ao invés disso ele mesmo pode agora ficar para trás, como o todo que se abre contra o negro pano de fundo da noite fechada. Esse todo agora fala com os humanos diretamente, livre do efeito de silenciamento da tradição e mitos, apenas por isso ele busca ser aceito e ser responsável. Nada da antiga vida de aceitação permanece em paz; todos os pilares da comunidade, tradição, e mitos são igualmente instabilizados, assim como todas as respostas que antes precederam perguntas, o modesto, já seguro e calmante significado está agora não perdido mas transformado (Patočka, citado por Adams, 2012, p. 7 , tradução nossa). ${ }^{5}$

\footnotetext{
${ }^{5}$ Such life does not seek to escape its contingency, but neither does it yield to it passively; since it has glimpsed the possibility of authentic life, that is, life as a whole, the world opens itself to it for the first time-it is no longer merely an involuntary background against which that which concerns us shows itself; rather it itself can now stand forth, as the whole of that which opens up against the black backdrop of closed night. This whole now speaks to humans directly, free of the muting effect of tradition and myth, only by it do they seek to be accepted and held responsible. Nothing of the earlier life of acceptance remains in peace; all the pillars of the community, traditions, and myths, are equally shaken, as are all the answers that once preceded questions, the
} 
Um ponto importante a ser destacado sobre o pensamento do autor é a ideia de que o que é (what-is) e o ser (being) se dão no mesmo plano, entre fenômeno e sua manifestação. A experiência e sua metáfora simbólica está no nível do fardo diário do viver e do fazer jus a nossos ancestrais. E para entender melhor suas ideias, recorremos ao seu entendimento do que seja história e pré-história.

Patočka entende história como ruptura e esta se inicia quando o homem começa a problematizar sua condição humana e considera que a vida em liberdade é superior ao mero sobreviver. É com a problematização que iniciará incontáveis buscas que resultam em ciência, tecnologia, exploração de outros mundos, psicanálise, biociência... ainda que estes resultados sejam atribuídos ao século XX já estavam fundamentados no início da história, no despontar da civilização ocidental (que datam dos sofistas e Platão). Na leitura de llea (2013), o entendimento de história e pré-história, bem como a noção de responsabilidade envolvida na transição de pré-história para história são fundamentais para entender a teoria do autor.

Para Patočka, pré-história está relacionado com uma visão de mundo e não com a graduação tecnologia existente. E por isso aponta a pólis Grega como início da história, é nela que se constrói um específico modo de humanidade baseado na problematização, na finitude enquanto problema, na "consciência desintegrada". Baseada também na completa consciência da morte, a aceitação problemática da condição humana e sua busca por eternidade via ações e política, filosofia, poesia etc. Esta ideia se opõe ao modo anterior que não destacava o individual e no qual o coletivo prevalecia via ideia de mundo governado por deuses e cooperação em rituais. E assim, nesta perspectiva, a história não é uma sobreposição à trajetória humana, é na verdade uma ruptura, uma diferenciação.

O destaque então é para o momento de emergência da consciência da problematicidade, quando a vida se torna "desabrigada" e inicia a história em oposição à pré-história (caracterizada por: aceitação, transmissão, preservação e manutenção da segurança da vida). Na história a vida perde seu abrigo pois há uma tensão constante de exposição ao risco e extremo esforço para sair desse abrigo de preservação e aceitação. Por não se tratar de nível de sofisticação tecnológica, sociedades como o Egito, antiga China e Oriente Próximo são pensadas como pré-históricas pois são como grandes famílias que preservam o estilo de vida da pré-história baseado em harmonia com o entorno e de não problematização deste ambiente. A sociedade histórica se diferencia da natureza e da simplicidade. Na pré-história, não se diferenciava noite e dia com base na experiência da

modest, yet secure and soothing meaning, though not lost is transformed (Patočka, citado por Adams, 2012, p. 7). 
escuridão mas como manifestações de seres que aconteciam no mesmo lugar e de modo simultâneo.

Dentre os três movimentos apresentados, o de transcendência, representa essa condição humana em toda sua plenitude e ao mesmo tempo seus riscos. O movimento aceitação é de submissão à natureza, de animal laborans, já o defence é o que nos motiva rumo ao êxtase de participar no indiferenciado (lembrar da interrelação com auto-projeção). No caso o terceiro movimento, em nome da busca da verdade, envolve distanciamento e reação contra a pré-história. Não só um distanciamento da pré-história, mas história, como uma tentativa de renovar a vida, um ressurgimento.

Sendo a história uma ruptura com a ideia de cotidianeidade da pré-história, emerge da passagem de uma a outra uma necessária responsabilidade. Na história o eu é entendido como parte de um grande projeto de responsabilidade pela tentativa de "cruzar a fronteira" do próprio eu para se perguntar quem somos de forma particular (ou quem somos em nossa inteireza), cruzar essa fronteira traz um aspecto impossível ao eu da pré-história. O eu em tempos pré-históricos é multicamada, uma delas inacessível a nós mesmos mas visível aos outros, e assim não temos completo acesso à verdade pois uma parte dela pertence a outros, o modo de agir fica vinculado a uma força de grupo, não somos completamente senhores de nós mesmos, o modo como apareço para outros diverge do modo de minha imagem pessoal da qual parto para agir e reagir. $\mathrm{O}$ autor desenvolve a metáfora de daimon para o entendimento do eu multicamada.

O nosso eu é inerentemente conectado a nós e ao mesmo tempo radicalmente distante de nós. Assim, daimon é a parte do eu que sem responsabilidade, e porque na préhistória nossa ação só ganha personalidade quando está ligada à comunidade, é invisível a nós mesmo mas visível aos outros. É por isso que Patočka entende que em tempos préhistóricos a verdade pertence aos outros. Não temos completo acesso à verdade porque não estamos confrontados com a decisão da responsabilidade. O autor trabalha a passagem de um estágio a outro da seguinte maneira:

A passagem para a responsabilidade é primeiramente um ato individual (ver A conversão de Abraão em Temor e Tremor de Kierkegaard). Originalmente, não é um ato completamente racional, uma questão de conhecimento de "bem" como era no Platonismo. A fim de realizar uma passagem de uma responsabilidade individual para uma responsabilidade coletiva, é preciso um coerente projeto racional. Essa passagem é uma questão de "conversões não mundanas" individuais. - como o amor e o encontro da morte - que se tornam uma coletiva "ocorrência mundana" - por exemplo respeito, direitos civis e regulamentos religiosos. A ponte entre $o$ ato individual e a responsabilidade coletiva implica 
uma transformação racional. No centro do projeto de responsabilidade, há uma "segredo" individual, uma decisão pessoal de obedecer algo que uma pessoa sozinha não abrange. A passagem para a racionalidade acontece através de uma experiência excedente de assumir a responsabilidade (llea, 2013, p. 339, tradução nossa). ${ }^{6}$

Responsabilidade está pensada como possibilidade de superar a cotidianeidade (everydayness), com vontade de superar o "mero viver" que se reforça cotidianamente o ser humano tenta participar, seja através de seu eu multifacetado, seja através de decisões éticas. Suas conquistas advêm deste movimento de tentar superar o mero viver da cotidianeidade, e este movimento pode vir tanto do fervor entusiástico em direção ao sagrado quanto da responsabilidade calcada na genealogia do eu que não mais aceita rituais, regras ou cosmogonias. A responsabilidade do indivíduo vem de sua consciência dessa condição histórica.

Neste sentido, a natureza do homem envolve tanto os três movimentos, quanto a consciência de suas interrelações na produção da história. A autenticidade do viver estaria na consciência de qual projeto fazemos parte ao nos afastar do conforto do indiferenciado pré-histórico em direção à superação da cotidianeidade. No nosso caso ocidental, a consciência de nosso processo de problematização que nos levou ao atual mundo, seria o caminho de responsabilidade, entender que problematizar é um projeto. Neste projeto, nos confrontamos com a morte, o que fez da nossa finitude um problema). Mas este é apenas um dos mundos possíveis, em possibilidade existem também outros, como o que se constrói via mistério e vê sua responsabilidade ligada à noção de morte e renascimento (do reino do mágico e das crenças não racionais).

Assim, quanto à pergunta de Učnik, sobre o porque de quando não falamos em ciência estarmos necessariamente falando em crença (sem nenhuma outra gradação possível), podemos perguntar de volta se a própria ciência que se guia como a verdade, não é também uma crença criada numa base (ground) específico (assim como outras crenças que seriam possíveis nascer de outra base de pensamento específico) e que em seu projeto, na sua noção de progresso, em seu regime de historicidade, entendeu como mais importante a liberdade de questionamentos a adaptar-se à simplicidade dos ritmos terrenos,

\footnotetext{
${ }^{6}$ This passage to responsibility is primarily an individual act (see Abraham's conversion in Kierkegaard's Fear and Trembling). Originally, it is not altogether a rational act, a matter of knowledge of the good as it was in Platonism. In order to accomplish the passage from an individual to a collective responsibility, there is the need of a coherent rational project. This passage is a matter of individual "unworldly conversions", — like love and the encountering of death - which become collective "worldly occurrences" - for instance respect, civil rights, and religious regulations. The bridge between the individual act and the collective responsibility implies a rational transformation. At the core of the responsibility project, there is an individual "secret", a personal decision to obey something that one does not fully encompass. The passage to rationality goes through an exceeding experience of assuming the responsibility (llea, 2013, p. 339, grifos nossos).
} 
ou ainda, desconsiderando o caráter coletivo dos horizontes históricos (pensados aqui como enunciado por Patočka, a verdade da condição humana), não entende a problematização como um projeto e, por isso, perde a noção de responsabilidade envolvida no movimento de sair da cotidianidade da pré-história.

Hartog (2003) aponta como a alteração da organização histórico-temporal é um sinal de crise e, assim como se viu crescer o presentismo no pós regime moderno de historicidade, logo já se percebeu a queda desse modo de organização que parece não dar conta de movimentos humanos de projeção (expresso na necessidade de previsão, futuro) e reconhecimento (criação de identidade, passado). Ao que nos parece, Patočka entendeu essas necessidades e as afirma justamente como movimentos de transformação de nossa natureza humana e, assim, propõe uma responsabilidade como forma de conectar de forma mais homogênea tanto movimentos individuais de criação de futuro, presente e passado com movimentos coletivos de construção de futuro, presente e passado; no projeto de transformação dos movimentos individuais em horizontes históricos estaríamos conscientes da importância de cada um destes e nossa responsabilidade seria justamente não deixar que nenhum deles se sobreponha ao outro, eles devem ser transformados juntos, evitando assim, "na dança dos ritmos" histórico-temporais, a criação de falta de significados. A responsabilidade está em lembrar que a racionalidade é um projeto e, independente dos resultados que este projeto traga (independente do regime de historicidade que crie), é importante estar consciente de nossa condição, de nossa necessidade por movimentos de ancoragem, auto-projeção e posterior transcendência - movimentos da verdade da natureza humana. Reconhece-se uma vontade de participar no coletivo e ao mesmo tempo de manter a produção temporal individual.

A transcendência é apontada como a plenitude, é o movimento que traz autenticidade, consciência de como se dá o entrelaçamento dos três movimentos. Se no coletivo pré-histórico, governado por leis superiores de "aceitação", o indivíduo carrega a cotidianeidade como um fardo porque parte da verdade pertence "daimonicamente" aos outros; uma história sem responsabilidade, que não reconhece a problematização como um projeto, produz falta de significado e de orientação. E ao que parece, seguindo leitura de Hartog (2003) e a ideia de presentismo, esquecer os movimentos de transformação coletivos, resulta em exacerbação do individualismo, outro caminho que parece produzir inautenticidade. Transcendência traz plenitude mas também traz seus riscos e é nesse sentido que Patočka afirma que "há coisas pelas quais vale a pena sofrer", a responsabilidade é defender o desdobramento dos três movimentos que são a natureza e a liberdade humanas, já que razão não está oposta aos sentidos e "o mundo das coisas" mundanas e passageiras (no sentido platônico), observado pela razão, é tão real para o ser 
humano quanto o mundo ideal; assim como os movimentos da natureza humana individual envolvem a criação de horizontes transubjetivos - ou históricos.

\section{Referências}

Hartog, F. (2003). Tempo, História e a Escrita da História: a Ordem do Tempo. Revista de História, 148, 09-34. (Prof. Dr. Francisco Murari Pires, Trad.). Recuperado de http://www.revistas.usp.br/revhistoria/article/view/18952

Ilea, L. T. (2013) Heretical dimensions of self responsibility by Jan Patočka. Investigaciones Fenomenológicas, 4(1), 331-349. Recuperado de http://www2.uned.es/dpto_fim/InvFen/InvFen_M.04.../17_Tusa.pdf

Peixoto, M. G. (1998) A condição política na pós-modernidade: a questão da democracia. São Paulo: EDUC.

Teixeira, A. (1959, julho/setembro) Filosofia e educação. Revista Brasileira de Estudos Pedagógicos, 32(75), 14 -27. Recuperado de http://www.bvanisioteixeira.ufba.br/artigos/filosofia.html

Terril, J. (2014, 21 de março) Professor Jan Patocka. News from The Czech Center Museum Houston. Recuperado de http://www.czechcenter.org/VerticalResponseEmails/more/janpatocka.html

Učník, L. (2013, junho) Science and Lebenswelt. In: Komel, A., \& Ljubljana, H. Phainomena: Genealogies, 22, 84-85. Recuperado de https://www.hse.ru/pubs/share/direct/document/104621114

\section{Nota sobre a autora}

Gabrielle Mesquita Alves Rosas. Mestre em Arquitetura e Urbanismo pela Universidade Federal Fluminense e Geógrafa pela Universidade Estadual de Campinas. Participa do Grupo de Pesquisa em Geografia Humanista Cultural. E-mail: gab.violeta@gmail.com. 